1998

\title{
On the quantum and tempo of fertility
}

John Bongaarts

Population Council

Griffith Feeney

Follow this and additional works at: https://knowledgecommons.popcouncil.org/departments_sbsr-pgy

Part of the Demography, Population, and Ecology Commons, Family, Life Course, and Society Commons, and the International Public Health Commons How does access to this work benefit you? Let us know!

\section{Recommended Citation}

Bongaarts, John and Griffith Feeney. 1998. "On the quantum and tempo of fertility," Policy Research Division Working Paper no. 109. New York: Population Council. Version of record: https://doi.org/ $10.2307 / 2807974$ 


\section{On the $Q$ uantum and Tempo of Fertility}

John Bongaarts

Griffith Feeney

1998 No. 109 


\title{
On the Quantum and Tempo of Fertility
}

\author{
John Bongaarts \\ Griffith Feeney
}

John Bongaarts is Vice President, Policy Research Division, Population Council. Griffith Feeney is Senior Fellow, Program on Population, East-West Center, Honolulu. 


\begin{abstract}
Demographers have known since the 1940s that standard measures of period fertility, such as the widely used total fertility rate, are distorted by changes in the timing of childbearing. Period fertility rates are depressed during years in which women delay childbearing and inflated in years when childbearing is accelerated. This problem is usually ignored because there has been no generally accepted method for solving it. This study proposes a method for removing the tempo distortions from the total fertility rate. The key assumption of the method is that period effects, rather than cohort effects, are the primary force in fertility change, an assumption supported by past research. An application of the adjustment procedure to fertility trends in United States shows that concern over below-replacement fertility in the past 25 years has been largely misplaced. Without the distortion induced by the rising age at childbearing, the underlying level of fertility was essentially constant at close to two children per woman throughout this period. Below-replacement fertility in Taiwan since the mid-1980s is also largely attributable to tempo effects.
\end{abstract}

This material may not be reproduced in any form without written permission from the authors. 
Estimates of fertility are among the most widely used demographic statistics. In many developing countries recent levels and trends in fertility are avidly watched by policymakers, family planning program managers, and demographers to determine whether and how rapidly fertility is moving in the desired downward direction. In much of the developed world, where fertility is now at historic lows, these same statistics are examined for signs of an upturn in fertility back to the replacement level needed to prevent future declines in population size. Given this interest in measuring human reproduction, it is desirable for users of fertility statistics to understand the strengths and weaknesses of available indicators. It is particularly important to avoid basing policies on statistics that give potentially misleading information.

Although the demographic literature offers many measures of fertility, the total fertility rate (TFR) is now used more often than any other indicator. The TFR is defined as the average number of births a woman would have if she were to live through her reproductive years (ages 15-49) and bear children at each age at the rates observed in a particular year or period. It is a hypothetical measure because no real group of women has experienced or will necessarily experience these particular rates. The actual childbearing of cohorts of women is given by the completed fertility rate (CFR), which measures the average number of births 50-year-old women had during their past reproductive years. The CFR measures the true reproductive experience of a group of women, but it has the disadvantage of representing past experience: women currently aged 50 did most of their childbearing two to three decades ago when they were in their 20s and 30s. The advantage of the TFR is that it measures current fertility and therefore gives up-to-date information on levels and trends in fertility. Another reason for the popularity of the TFR is its ease of interpretation compared with some other measures. Most interested 
persons will have little difficulty interpreting fertility measures expressed in births per woman, but few non-demographers will know intuitively whether populations with a crude birth rate of 10 (births per 1000 population) or a general fertility rate of 100 (births per 1000 women of reproductive age) have high or low fertility.

The simplicity and wide availability of the TFR have contributed to a neglect of some deficiencies in this fertility indicator. The demographic literature on the measurement of fertility includes many criticisms of and alternatives to the conventional TFR, but there is no agreement on a replacement for it. In the next section we provide a brief selective review of the past halfcentury of demographic literature on the subject. This is followed by a proposal for arriving at an adjusted version of the TFR that is free of so-called tempo effects-distortions due to changes in the timing of births. The conventional TFR can be considered to consist of a quantum and a tempo component. We define the quantum component as the TFR that would have been observed in the absence of changes in the timing of childbearing during the period in which the TFR is measured. The tempo component equals the distortion that occurs due to timing changes. ${ }^{1}$ Our objective is to measure the quantum component by eliminating the tempo distortion from the conventional TFR. The resulting quantum measure will be called the tempo-adjusted TFR.

\section{BACKGROUND}

Critiques of the total fertility rate involve several common themes: the problems posed by changes in the timing of childbearing; the relationship between period and cohort measures; the nature and validity of period mea- 
sures interpreted as "hypothetical" cohorts; and the extent to which fertility measures should embody controls not only for age but also for such variables as parity, duration of marriage, or other demographic variables (Ní Bhrolcháin 1992). A penetrating early discussion of several of these issues was provided by Hajnal (1947). Analyzing "the recent international recovery of the birth-rate," he argued that the traditional method of analyzing fertility trends based on annual data is inherently defective and should be abandoned. The widespread practice of fertility control makes it possible for families to time the arrival of their children in accordance with whatever factors they deem relevant, as well as to limit the total number of children born, and "[u]nder such circumstances a change in the rate at which people are having children in a given year can no longer be taken as an indication of a change in the number of children they will bear altogether in the course of their reproductive lives" (p. 143).

Direct evidence that timing changes produced undesirable results was presented by Whelpton $(1945,1954)$, who used US statistics to disaggregate the TFR into its birth-order components, where the first-order component $\mathrm{TFR}_{1}$ is defined as the sum of age-specific first birth rates (first births divided by person-years lived by all women), and similarly for higher-order components. The $\mathrm{TFR}_{1}$ gives the average number of first births women would have by age 50 if they were to bear first births at the age-specific rates observed in a given year or period. By definition, the sum of all-order components equals the TFR.

In most years during the late 1940 s and early 1950 s the $\mathrm{TFR}_{1}$ in the United States exceeded 1, which would imply that women on average had more than one first birth (see Figure 1). Since this is impossible, these TFR 
estimates must be rejected or reinterpreted. In considering this puzzle, Whelpton noted but did not deal directly with the effect of timing changes. Instead he focused on inadequate standardization for parity as a potential problem, and he developed a life table procedure based on age-parity-specific birth rates to calculate the TFR implied by these rates. Around the same time, Louis Henry in France was developing a different life table procedure based on birth rates specific for parity and duration in parity (Henry 1980 [1953]). These approaches have been applied and extended in numerous later studies (e.g., Feeney and Yu 1987; Feeney et al. 1989; Ní Bhrolcháin 1987, 1992; Rallu and Toulemon 1994).

Life table procedures used to calculate fertility indicators that are standardized for parity (or duration in parity) do not address directly the distort-

Figure 1 Total fertility rate for the United States, all births and first births, 1945-90

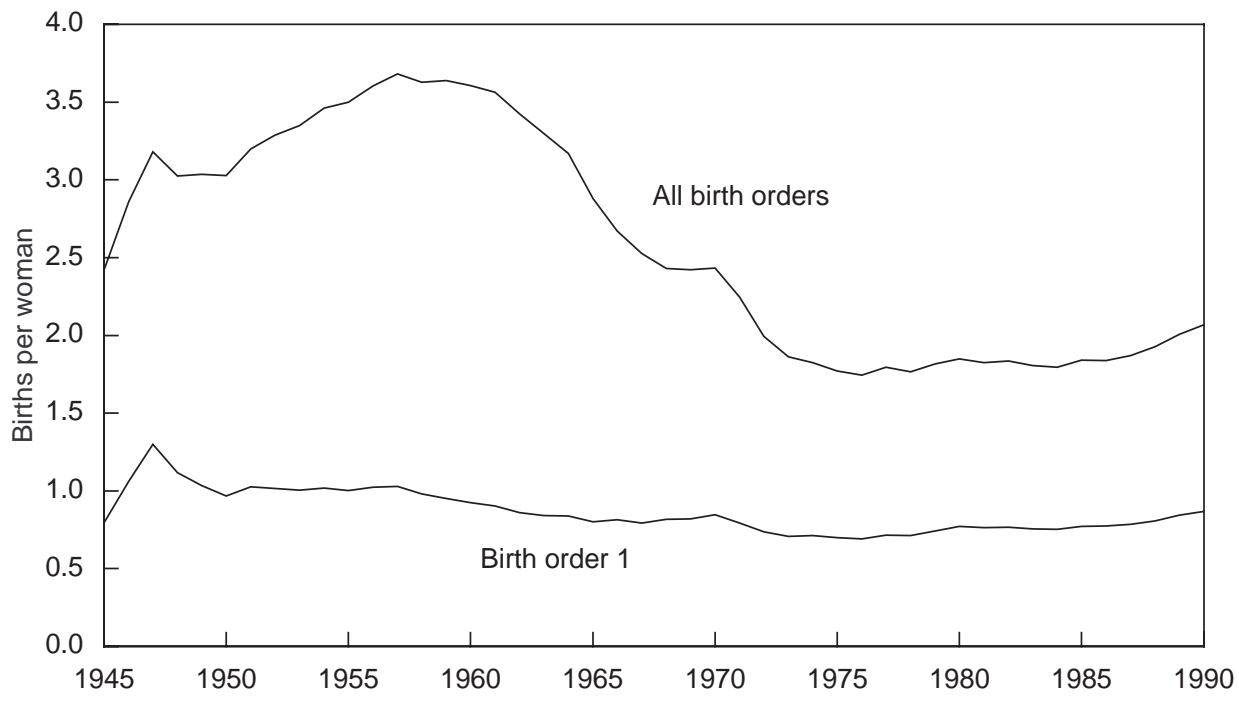


ing effects of changes in the timing of childbearing. During years in which women delay childbearing, fertility rates are depressed; and in years when childbearing is accelerated, fertility is raised. Because these effects depress or inflate numbers of births, they influence birth rates of all kinds-life table rates as well as ordinary age-specific rates and TFRs. Interestingly, life table procedures such as the one proposed by Whelpton remove at least partially the most obvious distortions of tempo effects on $\mathrm{TFR}_{1}$, because the $\mathrm{TFR}_{1}$ they produce no longer exceeds one. While this gives a more sensible result, it is an inevitable consequence of the life table calculations and does not provide a substitute for dealing directly with the timing distortions. ${ }^{2}$

An extensive analysis of the effects of variations in the childbearing tempo on period fertility indicators has been undertaken by Ryder in a series of influential papers (Ryder 1956, 1959, 1964, 1980, 1983). He demonstrated how changes in the timing of childbearing among cohorts of women in the United States influenced annual period measures of fertility such as the TFR. His 1956 article gave the basic "translation" equation relating the CFR (a cohort indicator) to the TFR (a period measure) in a population in which the mean age at childbearing changes linearly with increments of $c$ years per cohort:

$$
\mathrm{TFR}=\mathrm{CFR} *(1-c)
$$

For example, if the mean age at childbearing of successive cohorts increases by 0.1 year per cohort (e.g., from 27 years for one cohort to 27.1 for the next, etc.), then substitution in the above equation yields $\mathrm{TFR}=\mathrm{CFR} * 0.9$. In other words, a modest annual increase of one-tenth of a year in the mean age at childbearing results in a reduction in the TFR to 10 
percent below the corresponding CFR. Similarly, if the mean age were to decline annually by the same amount, the TFR would be inflated by 10 percent. In applications of this equation to fertility trends in the United States, Ryder has demonstrated that a substantial proportion of the post-World War II "baby boom" was due to declines in the age at childbearing during this period (Ryder 1980).

While Ryder's simple translation equation captures the main effect of tempo changes on period fertility, it has not found wide acceptance. Two main reasons may be suggested for this. First, Ryder assumes that the tempo and quantum of cohort fertility are the determinants of the TFR and other period fertility measures. However, extensive empirical analysis of this issue has demonstrated that this is not the case (Brass 1974; Page 1977; Foster 1990; Pullum 1980; Ní Bhrolcháin 1992). For example, Brass (1974) concluded that cohort completed fertility revealed no significant feature that distinguishes it from time averages of period indexes. A recent review of this literature by Ní Bhrolcháin reached a similar conclusion: "of the two dimensions of calendar time - period and cohort - period is unambiguously the prime source of variation in fertility rates" (1992: 600). Second, changes in the mean age at childbearing of aggregate cohorts do not accurately capture tempo effects when cohort fertility is declining. Cohorts reduce their fertility primarily by reducing childbearing at higher birth orders. As a result, the mean age at childbearing for all births declines even when the timing of individual births does not change. In other words, a decline in the cohort quantum leads to changes in the mean age at childbearing that do not represent true tempo effects. The above translation formula therefore gives incorrect results except when cohort fertility is constant. Fortunately, this second 
problem can be solved by applying the translation formula separately to each birth order rather than to overall cohort fertility. This option was proposed by Ryder (1959), who noted "the valuable gains in precision offered by this type of specificity" (p. 41), but for some reason Ryder largely ignored order specificity in subsequent work on the translation problem. ${ }^{3}$

\section{TOWARD A SOLUTION}

Fertility changes from one year to the next can occur at any age and birth order and can occur because of quantum as well as tempo effects. The information available in observed fertility rates may well be insufficient to disentangle quantum from tempo effects at all ages, orders, and durations. It is possible to make progress, however, by assuming that fertility changes in a structured way. Specifically, we will assume that fertility may be influenced by period, age, parity, and duration since last birth, but not by cohort. We will demonstrate that under this condition the total fertility rate that would have been observed in a given year had there been no change in the timing of births during that year may be estimated by dividing the observed $\mathrm{TFR}_{i}$ at each birth order by $\left(1-r_{i}\right)$ where $r_{i}$ is the change in mean age at childbearing at order $i$ during the year. This formula makes it possible to adjust the total fertility rate observed in any given year for effects attributable to the changing tempo of childbearing.

To demonstrate this result we begin with a highly stylized reference situation in which (i) only births of order one occur, (ii) all women in every birth cohort have their (first) births at a single exact age, (iii) all births occur at equal intervals during the year, and (iv) all cohorts have the same number of women. This situation is illustrated in Figure 2A, in which births (repre- 
Figure 2 Three illustrations of tempo effects on fertility

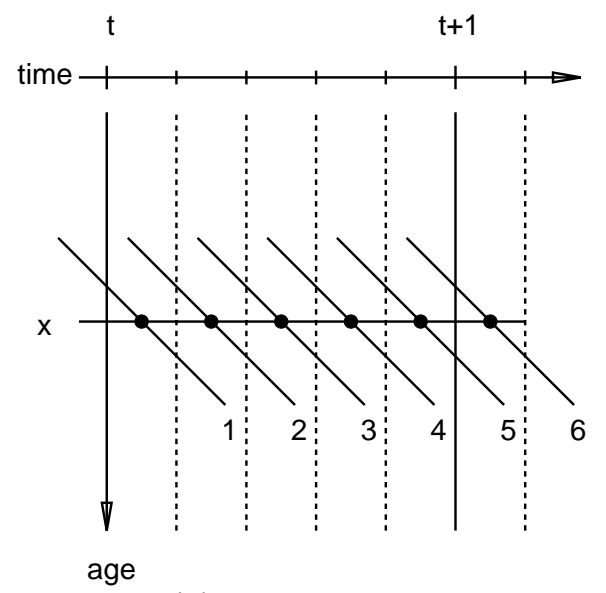

(A) No change in tempo

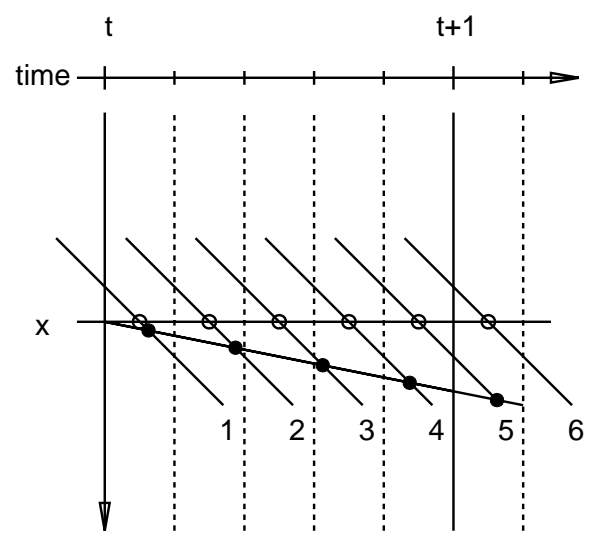

age

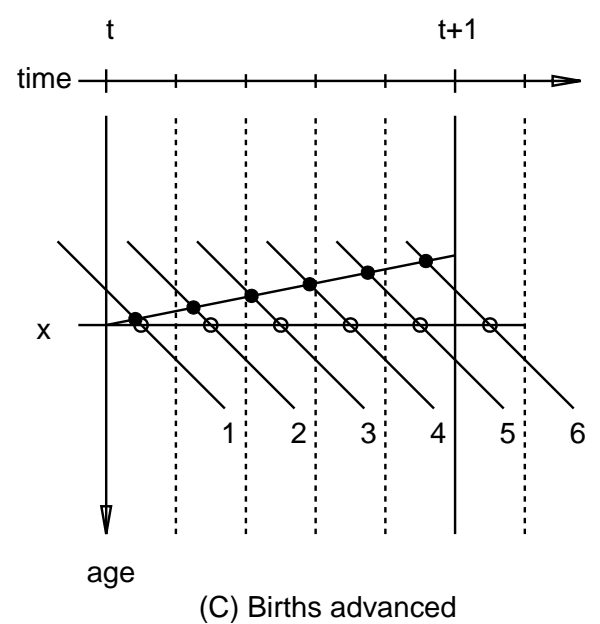

(C) Births advanced

Note: See text for explanation.

sented in all three panels by solid circles) occur at intervals of 0.2 years and cohorts $1,2, \ldots, 6$ all have their births at the same exact age $x$.

Suppose now that the mean age at birth increases by 0.2 years (i.e. from $x$ to $x+0.2$ ) during the year, ${ }^{4}$ as illustrated in Figure 2B. Achieving such a rise implies that births occurring at age $x$ in the reference scenario are now 
deferred. The extent of this delay increases during year $t$, with cohort 1 having the smallest and cohort 5 the largest delay. Because this delay shifts births to cohort 5 from year $t$ into year $t+1$, the number of births in year $t$ declines by 20 percent. Alternatively, suppose that the mean age at birth declines from $x$ to $x-0.2$ during year $t$, as illustrated in Figure 2C. Births to cohort 6 are now shifted into year $t$ and as a result the number of births in year $t$ rises by 20 percent.

Nothing in this argument depends on births in the reference situation occurring at intervals of 0.2 years, and we can reduce this interval to a value sufficiently small that the effective assumption is simply that births are uniformly distributed over time. With such a uniform distribution the number of births in year $t$ would also have been 20 percent lower with a rise of 0.2 years in the mean age and 20 percent higher with a decline of 0.2 years.

In general, then, a change of $r$ years in the mean age at first birth during year $t$ implies for this simple case that observed births may be expressed as $(1-r)$ times the births that would have been observed had there been no change in the timing of births. Inverting this relationship gives

$$
B_{a d j}=B_{o b s} /(1-r)
$$

where $B_{a d j}$ denotes the number of births that would have been observed if no tempo change had occurred and $B_{\text {obs }}$ denotes the observed number of births.

The assumption that all women in each cohort have their first births at a single age simplifies the diagrams in Figure 2 and makes the result relatively transparent, but it is not essential to the argument. The argument applies in precisely the same way if births occur not just at age $x$ but at any age. Imagine a copy of Figure 2B or 2C reproduced for every age $x$ at which 
births occur, and it will be clear both why the initial assumption is made and why it is not essential. In relaxing the assumption of all births occurring at the same age, however, we must introduce the assumption that tempo changes are the same for births occurring at any age. In less formal, more substantive terms, we must assume that women of all ages bearing children in year $t$ defer or advance their births to the same extent independently of their age or cohort identification.

The argument above has been made for first births only, but it applies equally to births of other orders (and more generally to any non-recurring event). We shall see in the empirical application that it is essential to apply the adjustment formula to births of each order separately and combine the results to obtain an estimate of the tempo effect for all births.

To this point we have focused on the impact of tempo changes while ignoring quantum effects. Quantum effects refer to variations in fertility over time that occur even if the mean age at childbearing remains invariant. Fortunately, it is possible to distinguish a change in the annual number of births resulting from a quantum effect from a change resulting from a tempo effect. Changes in tempo are illustrated in Figures $2 \mathrm{~B}$ and C. Changes in quantum are easily incorporated. Imagine the situation illustrated in Figure 2A, but suppose that births, instead of being constant, decline with each successive cohort. For example, let births to cohorts 1-5 in Figure 2A decline linearly over time while the ages at which births occur remain the same. If the rate of this change is properly chosen, it will result in 20 percent fewer births in year $t$, identical to the reduction illustrated by Figure 2B. Although the observed number of births of order one is identical in these two situations, it is possible to distinguish between them because the tempo effect involves a change in the mean age at childbearing and the quantum effect does not. 
The results obtained thus far have referred to numbers of births, rather than to birth rates; clearly we want to extend them to birth rates. The results for numbers of births are important, however, for they establish something that might otherwise remain obscure. Period fertility measures may be calculated in many ways, and different measures have different properties. Since the effects of changes in birth timing operate on numbers of births occurring during a year or other period, that is, on the numerators of birth rates, the distortions induced by these changes will be observed in most other measures of period fertility, no matter how finely women have been categorized by age, parity, and other relevant variables, and whether or not the calculation involves ordinary summation of rates or calculations of the life table type. ${ }^{5}$ Only a method that explicitly adjusts for the distortions induced by changing tempo can control these biases.

Extending the adjustment formula derived for numbers of births to total fertility rates and other relative measures is straightforward in principle, if tedious in detail. As shown in the Appendix, the adjustment formula for the total fertility rate at order $i$ is the same as for numbers of births:

$$
\mathrm{TFR}_{i}=\mathrm{TFR}_{i} /\left(1-r_{i}\right)
$$

where $\mathrm{TFR}_{i}$ is the observed total fertility rate in any given year, $r_{i}$ is the change in mean age at childbearing at order $i$ between the beginning and end of the year, and TFR' ${ }_{i}$ is the total fertility rate that would have been observed had there been no change in the timing of births. The adjustment made to TFR $_{i}$ depends solely on the timing changes during the year in which $\mathrm{TFR}_{i}$ is measured, and it is independent of timing changes before or after this year. Summing over all birth orders gives the adjusted TFR': 
These equations can also be applied to periods longer or shorter than one year, provided $r_{i}$ equals the annualized rate of change in the mean age at childbearing at order $i$.

Most discussion in the demographic literature draws a simple and familiar dichotomy between "period" and "cohort." It is evident that a notion of "deferring" or "advancing" births necessarily refers at some level to cohorts. The births that are advanced or deferred are attached to the women who are their mothers, and the mothers have them earlier or later in time, and hence at younger or older ages. This is the language of cohorts, not of periods. On the other hand, our formulation of quantum and tempo effects is a period formulation. No reference is needed to anything that happens before or after the period with which we are concerned. Changes in tempo and quantum are assumed to be period-specific and not to vary with age or cohort. This implies that the shape of the age distribution of period fertility (at each birth order) remains invariant, but this distribution shifts to higher or lower ages over time when tempo effects are present. Young women and old women, later cohorts and earlier cohorts, are all assumed to respond in the same way to period influences on tempo. This is a strong substantive assumption, but it is consistent with the empirical evidence cited by Ní Bhrolcháin (1992), if in marked contrast to the cohort emphasis that suffuses the work of Ryder. It is likely that our assumption is in practice violated during certain years (e.g., in wars, famines, etc.) when fertility changes rapidly and suddenly from one year to the next and cohort effects are not negligible. The above adjustment formula should not be used during such periods. 


\section{APPLICATIONS OF THE ADJUSTMENT FORMULA}

\section{United States}

The United States is in many respects an ideal test case for the application of the tempo adjustment formula. The pioneering work of Whelpton (1954), continued by Heuser (1973) and subsequently by the National Center for Health Statistics in the annual US vital statistics publications, provides a time series of age-order-specific birth rates for single years of age covering most of the twentieth century, during which there have been broad swings in both the level and timing of childbearing. Although a thorough analysis of this extensive empirical evidence would require far more space than is available here, it is ideal for illustrating the application of the adjustment procedure.

From the age-order-specific birth rates in Heuser (1976), updated through 1991 by the annual US vital statistics publications, we compute $\operatorname{TFR}_{i}(y)$ and $\operatorname{MAC}_{i}(y)$ for birth orders $i=1, \ldots, 7$ and $8+$ and for years 195090, where $\operatorname{MAC}_{i}(y)$ denotes the mean age at childbearing at order $i$ in year $y$. From the $\mathrm{MAC}_{i}(y)$ values we compute an annual series $r_{i}(y)$ of rates of change in mean age at childbearing for births of each order, and from these we obtain the adjusted TFR' $(y)$ with equation $(3) .^{6}$

Figure 3 compares the observed and tempo-adjusted TFRs for the years 1950-90. Between 1950 and 1962, from the beginning of the baby boom to slightly past its peak, declining age at childbearing pushed unadjusted total fertility well above the adjusted values. From 1963 through 1987, however, increasing age at childbearing pushed unadjusted total fertility below the adjusted values. During the last three years of the comparison, age at child- 
bearing was virtually unchanged overall and the adjusted and unadjusted values are essentially equal.

"Age at childbearing" here is multidimensional, represented not by a single index (such as the mean age at childbearing), but by the mean age at childbearing for births of each order. When we speak of "increasing" or "decreasing" age at childbearing, therefore, we necessarily refer to the overall tendency of these birth-order-specific mean ages, which do not necessarily change at the same rate.

Although this multidimensional character of tempo complicates the analysis, it is unavoidable. There were large changes in the quantum of higherorder births in the United States during this period, and since higher-order births occur on the average at older ages, these changes affected the mean

Figure 3 Observed and adjusted total fertility rate for the United States, 1950-90

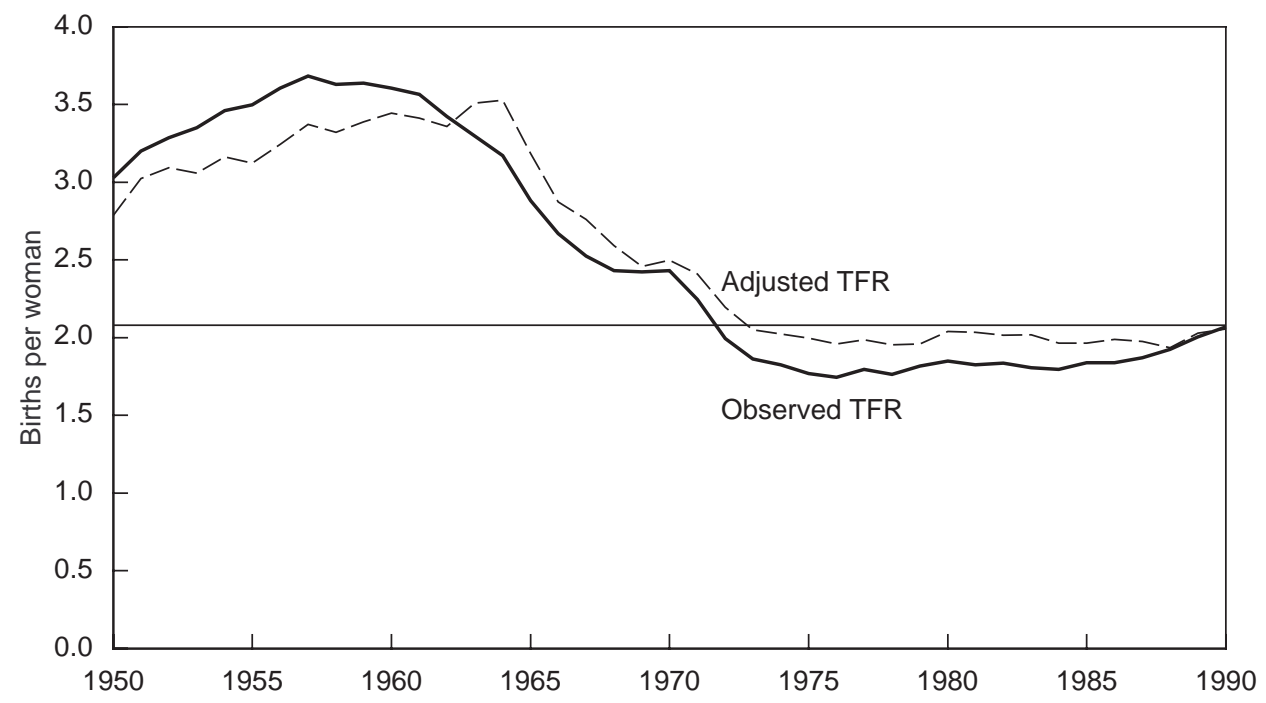


age at childbearing for births of all orders independently of changes in tempo. To see the importance of this consideration, note that mean age at childbearing for births of all orders may be expressed as a weighted average of mean age at childbearing for births of each order. For any year $y$, for example, we may write:

$$
\mathrm{MAC}=\mathrm{MAC}_{1} \mathrm{w}_{1}+\mathrm{MAC}_{2} \mathrm{w}_{2}+\mathrm{MAC}_{3} \mathrm{w}_{3}+\mathrm{MAC}_{4+} \mathrm{w}_{4+}
$$

where MAC denotes mean age at childbearing for all birth orders and $w_{i}=$ $\mathrm{TFR}_{i} / \mathrm{TFR}$. If $\mathrm{TFR}_{3}$ and $\mathrm{TFR}_{4+}$ decline more rapidly than $\mathrm{TFR}_{1}$ and $\mathrm{TFR}_{2}$, as was the case in the US during the 1960s and early 1970s, mean age at childbearing for all births will decline even if mean age at childbearing for births of each order is constant.

More generally, shifts in relative quantum at different birth orders can magnify, attenuate, and even reverse the trends implied by order-specific mean ages at childbearing. For example, between 1965 and 1974 the mean age at first birth in the United States rose from 22.39 to 22.64 years, the mean age at second birth rose from 24.91 to 25.57 years, the mean age at third birth rose from 27.42 to 27.95 years, and the mean age at fourth and higher-order births rose from 31.13 to 31.98 years. In other words, the mean age at childbearing rose for births of all orders taken separately, producing a clear tempo effect that depressed fertility. However, the mean age at childbearing for births of all orders actually declined from 26.55 to 25.74 years during the period as a result of large changes in the weights for different birth orders (see Figure 4). The quantum of higher-order births declined much more rapidly than the quantum of first and second births, so that the weight 
Figure 4 Mean ages of women at birth by birth order, United States, 1950-90

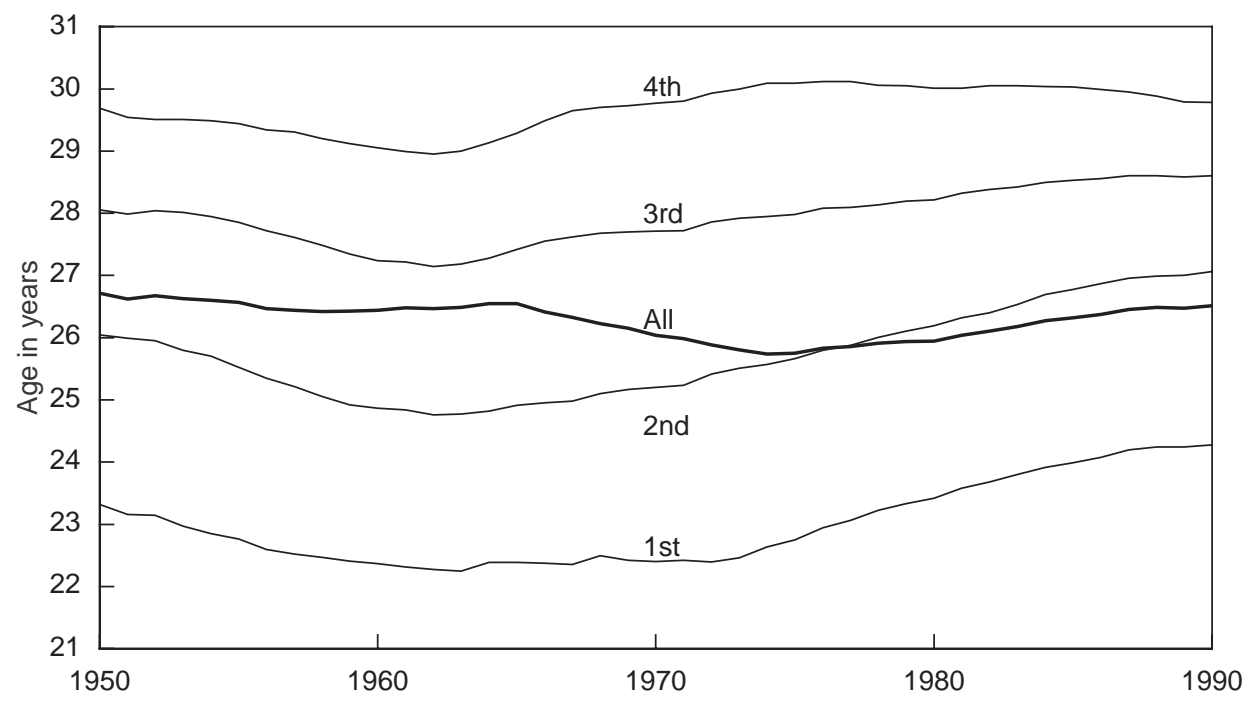

applied to first births in the above formula rose from 0.2782 to 0.3901 and the weight applied to second births rose from 0.2379 to 0.3118 . The weight for fourth and higher-order births, on the other hand, fell from 0.3041 to 0.1496 . The combined effect of these weight changes is so large that it more than offset the rise in the means at each order. Using a non-order-specific adjustment procedure in this case would not just get the magnitude of the adjustment wrong, it would adjust in the wrong direction, that is, it would give a less accurate result than no adjustment at all.

\section{Taiwan}

Taiwan is one of the few countries in the developing world with a vital registration system that is virtually complete. Detailed estimates of fer- 
tility rates by age and birth order since the mid-1970s are available in the annual Taiwan Demographic Factbook. From these data the observed and tempo-adjusted TFRs have been calculated for the period 1978 to 1993 in the same way as in the above illustration for the US. The results are summarized in Figure 5. The TFR declined sharply from 2.68 in 1978 to 1.66 in 1986 before recovering slightly to 1.76 by 1993 . Throughout this period the mean age at birth of all orders was rising, and the adjusted TFR therefore exceeds the TFR. The tempo effect amounts to about a quarter of a birth per woman in the late 1970s and early 1990s, but it was higher-about 0.4-in the mid and late 1980s when the change in the mean ages was most rapid. Although the observed TFR has been well below replacement since 1986, the adjusted TFR suggests that in the absence of tempo changes, reproduction would have been close to the replacement level.

Figure 5 Observed and adjusted total fertility rate, Taiwan, 1978-93

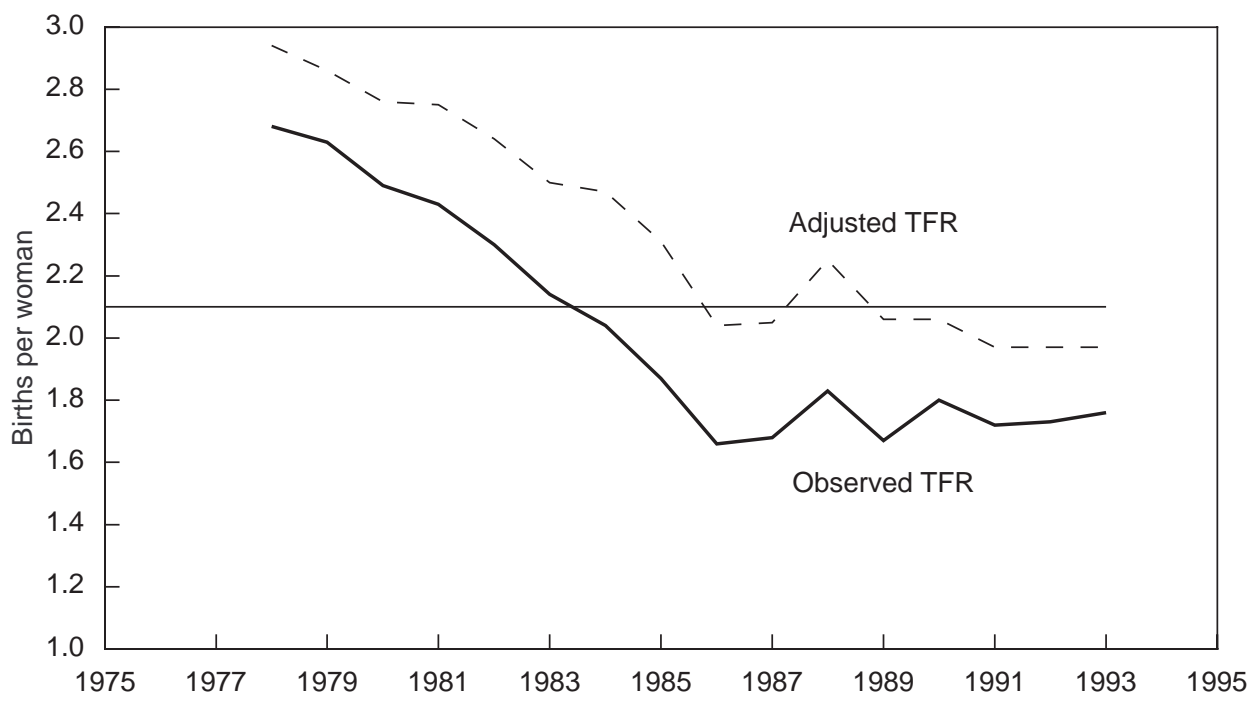




\section{A test of the adjustment formula}

The objective of the proposed adjustment procedure is to estimate the quantum component of the TFR. There is no direct way to test the accuracy of the TFR' $(y)$ values for individual years, but an aggregate test is feasible, as will be demonstrated next.

The test consists of a comparison of the completed fertility of true cohorts (which is a pure quantum measure) with an average of the adjusted total fertility rates (also a quantum measure) over the years during which the true cohorts were in their childbearing years. To illustrate this comparison, examine first a hypothetical case in which only first births occur and fertility does not change over time. All women who enter the childbearing years are assumed to bear exactly one child, but the average age at which this child is born rises at a rate of 0.1 year per year. In such a hypothetical population, the total fertility rate measured during any year would be 0.9 births per woman even though the cohort fertility measured at the end of the reproductive years would indicate a CFR of 1 birth per woman. By applying the adjustment formula to remove the tempo effects, we find that TFR' $=1$, which is equal to the observed CFR, thus confirming that the adjustment is accurate.

In actual populations an analogous test can be carried out by comparing the (order-specific) completed fertility $\mathrm{CFR}_{i}$ observed when true cohorts reach age 50 with the (weighted) average of the TFR' ${ }_{i}(t)$ values in the years during which the cohort did its childbearing (ages 15-49). ${ }^{7}$ For example the CFR1 of the cohort born in the United States in 1935 was 0.918, which implies that when this cohort reached the end of its childbearing years (in 1985) 91.8 percent of these women had a first birth and 8.2 percent remained childless. This estimate can be compared with the weighted average of the 
$\mathrm{TFR}_{1} \mathrm{~s}$ for the years 1950 to 1984 , which equaled 0.902 births per woman. Similar comparisons were made for the other birth-order components of this cohort, and the agreement is again good as shown in Figure 6.

A comparison of CFR and TFR' has been carried out separately for all cohorts born from 1904 to 1941, and the results of this exercise are summarized in Figure 7. The observed completed fertility rates are generally very close to the corresponding weighted averages of TFR' $(t)$, with the average difference for these cohorts amounting to 0.051 births per woman. Figure 7 also shows the weighted average of the unadjusted total fertility rates for comparison. These show much poorer agreement with observed cohort fertility. If adjustments in the war years 1943-45 (when the assumption on which our procedure is based was violated) are excluded, then the fit is even better

Figure 6 Observed and estimated completed fertility by birth order for the cohort of US women born in 1935

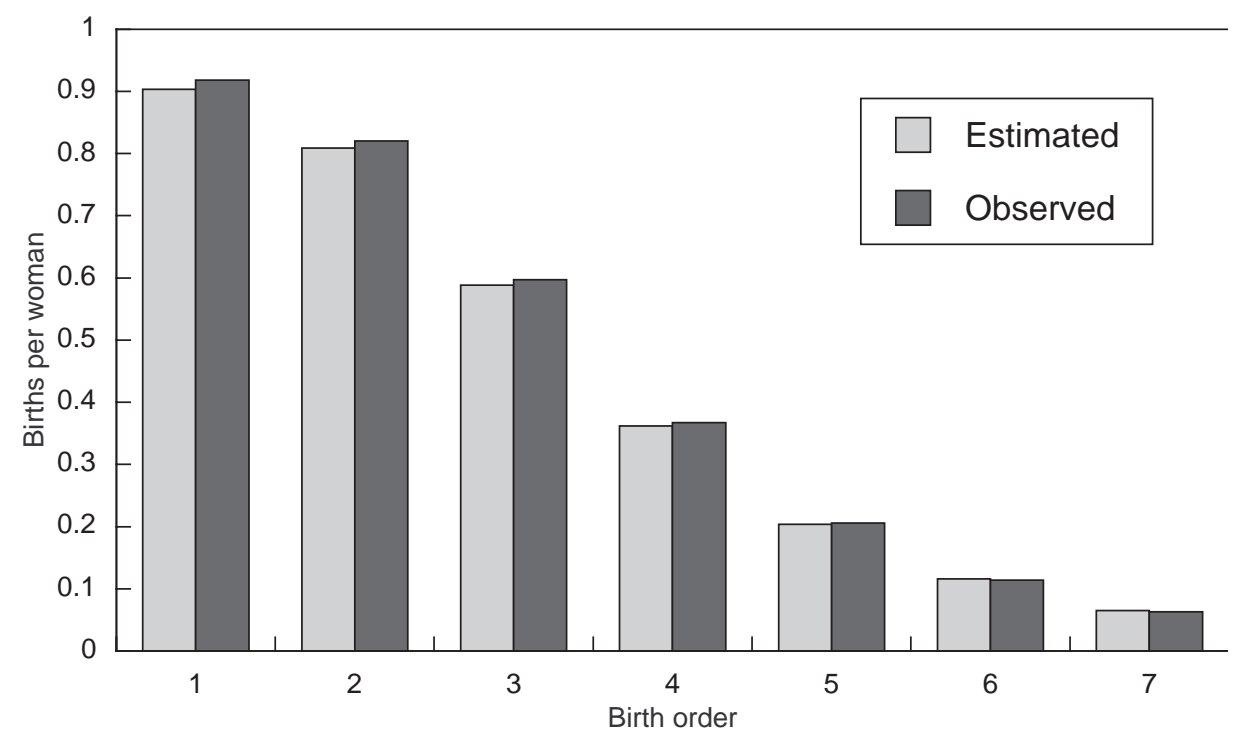


Figure 7 Observed and estimated completed fertility of cohorts of US women born 1904 to 1941

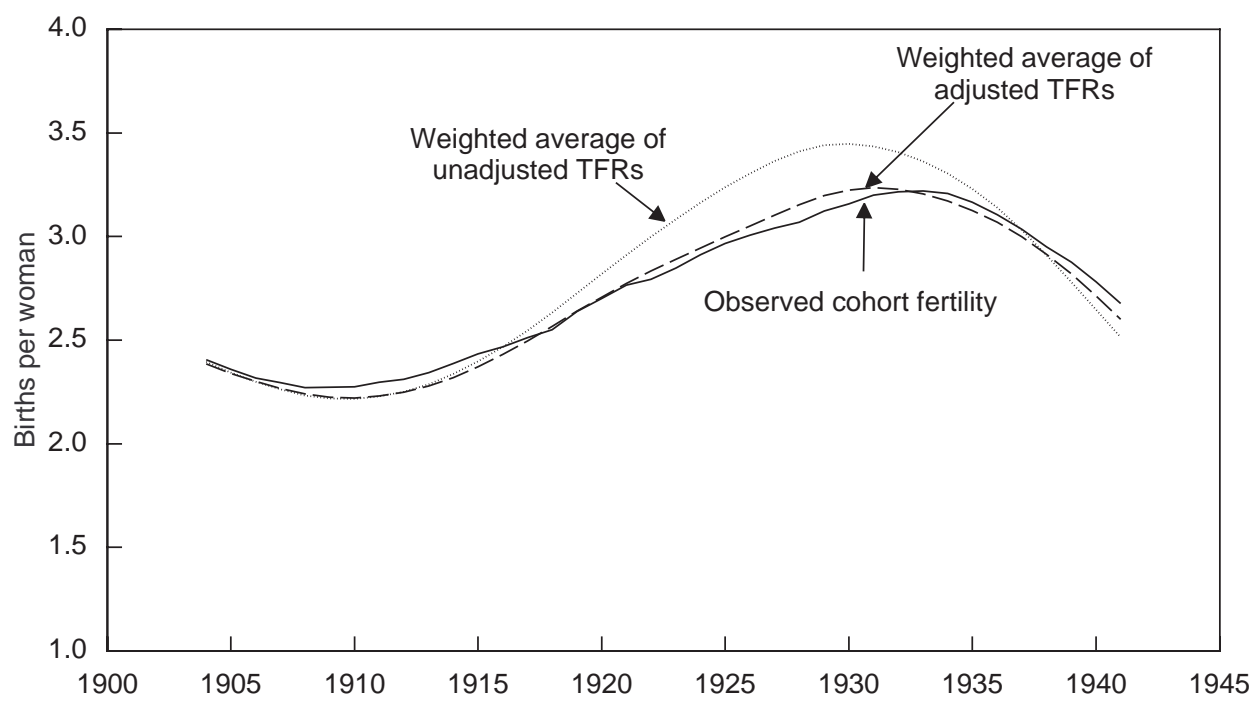

and the average difference is just 0.041 births per woman. These findings provide confidence in the accuracy of the adjustment procedure proposed in this study.

\section{CONCLUSION}

For half a century demographers have known that standard measures of period fertility, such as the widely used total fertility rate, are distorted by changes in the timing of childbearing. The fertility rates we are accustomed to using frequently give an inaccurate indication of the level of completed fertility implicit in current reproductive behavior because numbers and rates of births are depressed during years in which women delay childbearing and inflated in years when childbearing is accelerated. Ryder has argued persua- 
sively that the tempo distortion inherent in the conventional period fertility measures is a serious problem that deserves more attention. In practice, however, most uses of the total fertility rate effectively ignore the problem because there has been no generally accepted method for solving it.

The method proposed here has been shown both by theoretical argument and by empirical example to be an effective solution to the problem of adjusting total fertility rates for distortions attributable to changes in the tempo of childbearing. This approach is feasible, of course, only by maintaining certain assumptions about patterns of fertility change, and there will always be particular circumstances, such as the disruptions of World War II, in which these assumptions break down. No methodology can avoid the necessity for intelligent application. The essential assumption of the method proposed here is that period effects, rather than cohort effects, are the primary force in fertility change, an assumption supported by past research.

In some circumstances, of course, the conventional, unadjusted TFR will be the measure of choice despite tempo effects. If we are concerned with changes in numbers of births and the implications for future age distribution, for example, no tempo adjustment is called for. For most purposes, however, we are interested in the quantum component of the total fertility rate because it provides a better indication of the level of completed fertility implied by current fertility behavior, and hence a better answer to the question of how many births women will have if current childbearing behavior continues into the future. ${ }^{8}$

We have seen that tempo distortions are substantial and prolonged in both the United States and Taiwan. In general, tempo distortions exist as long as the timing of childbearing is changing. The issue of whether and to 
what extent fertility is depressed by tempo effects is a crucial one in many other countries. For example, by the mid-1990s the TFR in virtually every developed country had dropped below the replacement level of 2.1 births per woman and in some cases even below 1.5 (e.g., in Italy, Spain, and Germany). If such low levels of fertility are maintained, they will eventually lead to declining population size and extreme population aging. Declining population size would be salutary from some points of view, but rapid population aging is likely to pose profound social and economic problems. By extrapolating current low levels of fertility into the future, analysts often unwittingly ignore the fact that these rates are temporarily depressed by a rising age at childbearing. Eventually, the age at childbearing will stop rising and the removal of this fertility-depressing effect might well result in a rise in the TFR, as in fact happened in the United States in the late 1980s.

Our analysis shows that concern over below-replacement fertility in the United States in the past has been largely misplaced. The appearance of belowreplacement fertility throughout much of the 1970s and 1980s was entirely due to an increasing age at childbearing. Adjusting for the distortion induced by this change shows that the underlying level of fertility was in fact essentially constant at close to two children per woman throughout this period.

The new tool provided here affords analysts a better measure of women's true propensity to bear children in various countries. The distorting effects of a changing tempo of childbearing on fertility measures are too important and widespread to continue to ignore them in assessments of fertility behavior and its implications for future population growth. Tempoadjusted total fertility rates should be added to the existing set of fertility measures used to assess fertility trends. In many if not all circumstances they 
will do a better job of doing what conventional total fertility rates do poorly in the presence of tempo changes: reveal the level of completed fertility implied by current childbearing behavior.

To be sure, practical matters need to be addressed before such measures can be widely produced. Substantial tempo effects may exist in populations with high as well as low fertility, but the majority of the world's population is not covered by vital registration systems that generate the detailed data needed to compute the new measures. The fertility surveys from which statistics for developing countries are increasingly derived do not involve sufficiently large samples to be an effective surrogate. It is perhaps possible to develop census-based methods to assess tempo effects.

Surprisingly, data availability is a problem for some developed countries as well. In much of Western Europe, in particular, vital registration systems collect information on birth order within marriage, rather than for women. This was perhaps appropriate when most births occurred within marriage, but the large rise in births outside of marriage that began in a number of developed countries during the 1970s has rendered it increasingly inappropriate. When births are not firmly anchored to marriages, the woman, not the marriage, is the appropriate entity to which to attribute order of birth. Fortunately, national statistical offices are aware of this issue, and fertility statistics by true birth order are becoming increasingly available. Once fertility rates by true birth order are available, the calculations required to estimate a tempo-adjusted TFR are straightforward, though admittedly more cumbersome than for the conventional TFR.

It might be objected that tempo-adjusted total fertility rates are excessively "hypothetical" to be used as a routine addition to the demographer's 
repertoire of fertility measures. It is true that the rationale of their calculation involves assumptions about the patterns of fertility change that will never hold exactly, and we do not suggest that conventional total fertility rates (or other measures) be abandoned. There is a good dose of the hypothetical in the conventional total fertility rate, however, and we see the difference as one of degree rather than one of kind. The tempo-adjusted total fertility rate proposed here represents a technical result that can advance understanding of the level and trend of past fertility, and provides a firmer basis for projecting trends in future fertility.

\section{APPENDIX: DERIVATION OF THE TEMPO ADJUSTMENT FORMULA}

The discussion that follows focuses on births of a single order only; to simplify the notation, subscripts for birth order are deleted. The adjustment formula derived below is to be applied separately to births of each order to obtain corrected values of $\mathrm{TFR}_{i}$, which are then summed to obtain the adjusted TFR for all birth orders.

Let $f_{p}(t, a)$ denote a surface defined on the age-time plane of the Lexis diagram giving the age-specific fertility rates for women aged $a$ at time $t$. Let $f_{c}(T, a)$ represent the age-specific fertility rates at age $a$ for cohorts of women born at time $T$. Then

$$
f_{p}(t, a)=f_{c}(t-a, a) \text { and } f_{c}(T, a)=f_{p}(T+a, a)
$$

for any age $a$ and times $t$ and $T$. The period total fertility rate for time $t$ is

$$
\operatorname{TFR}(t)=\int f_{p}(t, a) d a
$$


and the completed fertility rate for the cohort born at time $T$ is

$$
\operatorname{CFR}(T)=\int_{c}(T, a) d a
$$

\section{Scenario 1: No tempo or quantum effects}

Suppose that $f_{p}(t, a)$ is constant with respect to $t$ for all $a$ (or, equivalently, that $f_{c}(T, a)$ is constant with respect to $T$ for all $a$ ), i.e., that age-specific fertility rates are constant. In this case fertility rates are solely a function of age: $f_{p}(a)=f_{c}(a)$ and TFR=CFR for all periods and cohorts. This is the reference situation in which there are no changes in quantum or tempo. A subscript $r$ will be added to fertility measures (i.e., $\mathrm{TFR}_{r}$ and $\mathrm{CFR}_{r}$ ) that refer to this scenario.

\section{Scenario 2: Time-invariant tempo effects, no quantum effects}

Beginning with Scenario 1, suppose that cohort fertility (quantum) does not change, but that from time 0 births are deferred, so that age at childbearing rises, and that the deferral occurs equally at all ages, so that the shape of the period age schedule $f_{p}(a)$ with respect to its mean does not change. The level of the period schedules in this second scenario will fall as a result of the deferral (or rise, if births are advanced instead of deferred). We want to find a procedure to determine the TFR that would have been observed in the absence of changes in timing (i.e., the Scenario $1 \mathrm{TFR}_{r}$ ) from the observed TFR in Scenario 2.

Let the surface of age-specific rates in this second scenario be denoted $g_{p}(t, a)$. By assumption, the shape of $g_{p}(0, a)$ is the same as $f_{p}(0, a)$. 
Moreover,

$$
g_{p}(t, a)=g_{p}(0, a-r t)
$$

which says simply that $g_{p}(t, a)$ has the same shape as $g_{p}(0, a)$, but has shifted up the age axis by $r t$ years (if $r$ is positive) or down the age axis by $r t$ years (if $r$ is negative). From (2) above it follows that for Scenario 2

$$
\operatorname{TFR}(t)=\int g_{p}(t, a) d a=\int g_{p}(0, a-r t) d a,
$$

i.e., that the period total fertility rate in this second scenario is constant over time. From (1) and (3) it follows that

$$
\mathrm{CFR}(\mathrm{T})=\int g_{c}(T, a) d a=\int g_{p}(T+a, a) d a=\int g_{p}(0, a-r(T+a)) d a,
$$

i.e., that the cohort fertility rate in the second scenario is constant over time. From (6), however,

$$
\begin{aligned}
\operatorname{CFR}(0)=\int g_{p}(0, a-r a) d a=\int g_{p}(0, a(1-r)) d a \\
=\int g_{p}(0, a(1-r))(1-r) d a \times 1 /(1-r)=\int g_{p}(0, a) d a \times 1 /(1-r) \\
=\operatorname{TFR}(0) /(1-r) .
\end{aligned}
$$

Since by assumption the completed fertility of cohorts in Scenario 2 is the same as in Scenario 1, the TFR in Scenario 2 may be estimated by multiplying the $\mathrm{TFR}_{r}$ in Scenario 1 by $(1-r)$. Alternatively, if Scenario 2 is observed, then the Scenario $1 \mathrm{TFR}_{r}$ can be estimated by dividing the observed TFR by $(1-r)$. 
Since the shape of the age pattern of period fertility in Scenario 2 is by assumption invariant and the same as in Scenario 1, it follows that

$$
g_{p}(t, a)=f_{p}(t, a+d)(1-r)
$$

where $d$ is the total number of years by which $g_{p}$ has been shifted relative to $f_{p}$ at time $t$. In other words, in Scenario 2 at time $t$ the original schedule of age-specific fertility rates has been moved along the age axis by an amount $d$ and has been multiplied by $(1-r)$.

\section{Scenario 3: Time-variant tempo effects, no quantum effects}

We do not expect ever to observe Scenario 2. It is rather a conceptual stepping stone to a more general result. Let $r(t)$ denote the rate at which the mean age at childbearing changes at time $t$. In Scenario 3 we let $r$ change with time, requiring only that $r(t)$ is piece-wise constant, i.e., is constant for $t$ in any given calendar year. As in Scenario 2, we want to ascertain what the TFR for any given year would have been had there been no change in age at childbearing, i.e., if $r(t)$ had been zero. In Scenario 3, however, the changing $r$ prevents us from doing the integration (7) that establishes the result for Scenario 2.

To establish the adjustment required in Scenario 3, we focus on a single year. From observed fertility in year $t$, we construct a fertility surface extending from the beginning of year $t$ through such time as the youngest women having children at this time cease having children, roughly 35 years. Equation (8) above applies to this constructed surface, 


$$
g_{p}(t, a)=f_{p}(t, a+d)(1-r(t))
$$

and integrating both sides over age yields

$$
\operatorname{TFR}(t)=\operatorname{TFR}_{r}(1-r(t))
$$

where $\operatorname{TFR}_{r}(t)$ denotes the TFR that would have been observed in year $t$ had there been no change in age at childbearing, i.e., if $r(t)$ had been zero. To see that this result applies to year $t$ considered in isolation, observe that (i) a value of $r(t)>0$ implies that $\operatorname{TFR}(t)$ will be lower than it would have been if $r(t)=0$ and that (ii) the magnitude of the effect depends only on the value of $r(t)$. Having observed given values of TFR $(t)$ and $r(t)$, then, and assuming that the value of $t$ is fixed throughout this year, we know that the same value of the TFR will be observed in the following year if the same $r(t)$ is observed in this year, and similarly for as many subsequent years as we care to specify. Having specified sufficiently many years into the future, we may carry out the integration of Scenario 2 to express the value of $\operatorname{TFR}(t)$ in relation to what would have been observed had there been no change in $r(t)$ during the year.

We have thus extrapolated the experience of a single year into the future and ascertained the implied cohort fertility. This is precisely what the customary TFR does, except that in the present case the extrapolation ignores the distorting effects of changing age at childbearing. By computing TFR $_{r}(t)$ we accomplish - subject to the assumptions of the adjustment procedure - what the customary TFR fails to accomplish unless there is no change of mean age at childbearing during the year. In particular, we are not 
attempting to predict cohort fertility, only to get an improved reading of period fertility.

\section{Scenario 4: Time-variant tempo effects with quantum effects}

This scenario is the same as the previous one except that the total fertility rate varies over time. Assume that $\operatorname{TFR}(t)$ as well as $r(t)$ is piece-wise constant, i.e., $\operatorname{TFR}(t)$ is constant during each calendar year, with the same assumptions as before about the age pattern of fertility. As in Scenario 3, a family of fertility surfaces is generated, one for each combination of values of TFR $(t)$ and $r(t)$. With the same derivation as in Scenario 3 we obtain

$$
\operatorname{TFR}(t)=\operatorname{TFR}_{r}(t)(1-r(t))
$$

and

$$
\operatorname{TFR}_{r}(t)=\operatorname{TFR}(t) /(1-r(t)) .
$$

This equation is used in this study to remove the tempo effect from the observed TFR(t) for different birth orders. 


\section{Notes}

The authors thank John Casterline, Samuel Preston, Jean-Louis Rallu, Norman Ryder, Carl Schmertmann, Laurent Toulemon, and Zeng Yi for their comments on an earlier draft of this paper.

1. In conventional use quantum refers to the average number of children born to women in a cohort, and tempo to the timing of births by age of mother within the cohort (Pressat 1985:191). Tempo is often measured by the mother's mean age at childbearing, but (for reasons given later) in our analysis tempo is measured by the mean ages at childbearing at each birth order. The absence of a tempo effect defined in this way implies that the mean ages at childbearing at each birth order remain fixed over time. The word "tempo" is in some respects unfortunate, suggesting occurrence at regular intervals that may be shortened or lengthened. No such regularity is implied in the formal demographic use of the term. Moreover, because "tempo" connotes a process occurring in time, like the ticks of a metronome, confusion may arise when speaking of "changing tempo," which in practice usually refers to changes in some measure of age at childbearing.

2. Another significant shortcoming of these life tables is the implied assumption of homogeneity of the population. All women at a given age, parity, and/or duration are assumed to have the same probability of childbearing no matter what their desire for more children or their fecundity status. This problem can in principle be addressed by separating the population into subgroups that are subjected to different risks of childbearing, but in practice a lack of data makes this solution difficult to implement. 
3. Hobcraft (1996) also notes the benefits of adjusting births at each order separately for removing timing distortions.

4. More specifically, suppose that births that occur at time $t+u$ in the reference situation are deferred to time $t+u /(1-r)$, where $r=0.2$.

5. The main exception to this statement is a situation in which all tempo effects are due to changes in the age at first birth while birth intervals are fixed. In that case higher-order parity progression ratios derived from birth rates by duration since last birth are not distorted by tempo effects. However, parity progressions to the first birth as well as the total fertility rates based on these parity progression rates are distorted. If the birth intervals are not fixed over time, then they are also affected by tempo effects (Brass 1990).

6. $\quad \operatorname{TFR}_{i}(y)=\sum \operatorname{AOSBR}(x, i, y)$ is simply the sum over ages $x=14-49$ of the age-order-specific $i$-th birth rates $\operatorname{AOSBR}(x, i, y)$ for birth order $i$ and year $y \cdot \operatorname{MAC}_{i}(y)=\Sigma \operatorname{AOSBR}_{x}(y)(y+0.5) / \operatorname{TFR}_{i}(y)$ is calculated using the usual midpoint approximation. To obtain a rate of change in $\mathrm{MAC}_{i}$ for calendar year $y$, we average the values for years $y-1$ and $y$ to obtain a value for the beginning of year $y$, and the values for years $y$ and $y+1$ to obtain a value for the end of year $y$, and subtract the latter from the former value. This reduces to $r_{i}(t)=0.5^{*}\left(\operatorname{MAC}_{i}(y+1)-\operatorname{MAC}_{i}(y-1)\right)$.

7. The weights are provided by the distribution of fertility in the years during which the cohorts are aged 20-35.

8. A statistic that provides a good indication of the average number of births per woman implicit in current childbearing behavior will also 
be a good indication of future cohort fertility if current childbearing behavior continues into the future. We do not necessarily expect current behavior to continue, however, and the objective is not to predict future completed cohort fertility, but to arrive at a period fertility measure that gives a demonstrably better indication of the level of completed fertility implicit in current behavior.

\section{References}

Brass, W. 1974. "Perspectives in population prediction: Illustrated by the statistics of England and Wales," Journal of the Royal Statistical Society A 137: 55-72.

. 1990. "Cohort and time period measures of quantum fertility: Concepts and methodology," in H. A. Becker (ed.), Life Histories and Generations, Vol. 2. Utrecht: University of Utrecht, pp. 455-476.

Feeney, Griffith. 1983. "Population dynamics based on birth intervals and parity progression," Population Studies 37: 77-89.

Feeney, Griffith and Jingyuan Yu. 1987. "Period parity progression measures of fertility in China," Population Studies 41: 77-102.

Feeney, Griffith, Feng Wang, Mingkun Zhou, and Baoyu Xiao. 1989. "Recent fertility dynamics in China: Results from the 1987 One Percent Population Survey," Population and Development Review 15: 297-322.

Foster, Andrew. 1990. "Cohort analysis and demographic translation: A comparative study of recent trends in age specific fertility rates from $\mathrm{Eu}-$ rope and North America," Population Studies 44: 287-315.

Hajnal, J. 1947. "The analysis of birth statistics in the light of the recent international recovery of the birth-rate," Population Studies 1: 137164. 
Henry, L. 1980. Fertility of Marriages: A New Method of Measurement, Population Studies Translation Series, No. 3. New York: United Nations. Originally published 1953.

Heuser, Robert L. 1976. Fertility Tables for Birth Cohorts by Color: United States 1917-73. DHEW Publication No. (HRA) 76-1152. Rockville, MD: National Center for Health Statistics.

Hobcraft, John. 1996. "Fertility in England and Wales," Population studies 50: $485-524$.

Ní Bhrolcháin, Máire. 1987. "Period parity progression ratios and birth intervals in England and Wales, 1941-1971: A synthetic life table analysis," Population Studies 41: 103-125.

- 1992. "Period paramount? A critique of the cohort approach to fertility," Population and Development Review 18: 599-629.

Page, H. J. 1977. "Patterns underlying fertility schedules: A decomposition by both age and marriage duration," Population Studies 30: 85-106.

Pressat, Roland. 1985. The Dictionary of Demography. Edited by Christopher Wilson. Oxford: Basil Blackwell.

Pullum, T. W. 1980. Separating age, period and cohort effects in white US fertility, 1920-70," Social Science Research 9: 225-244.

Rallu, Jean-Louis and Laurent Toulemon. 1994. "Period fertility measures: The construction of different indices and their application to France, 1946-89," Population: An English Selection 6: 59-94.

Ryder, Norman B. 1956. "Problems of trend determination during a transition in fertility," Milbank Memorial Fund Quarterly 34: 5-21.

1959. "An appraisal of fertility trends in the United States," in Thirty Years of Research in Human Fertility: Retrospect and Prospect. New York: Milbank Memorial Fund, pp. 38-49. 
- 1964. "The process of demographic translation," Demography 1: 74-82.

- 1980. "Components of temporal variations in American fertility," in R. W. Hiorns (ed.), Demographic Patterns in Developed Societies, London: Taylor \& Francis, pp. 15-54.

- 1983. "Cohort and period measures of changing fertility," in Rodolfo A. Bulatao and Ronald D. Lee (eds.), Determinants of Fertility in Developing Countries. New York: Academic Press, Vol. 2, pp. 737-756.

_ 1986. "Observations on the history of cohort fertility in the United States," Population and Development Review 12: 617-643.

Whelpton, Pascal K. 1945. "Effect of increased birth rate on future population," American Journal of Public Health 35: 326-333.

-1954. Cohort Fertility: Native White Women in the United States. Princeton, NJ: Princeton University Press. [Reissued 1973, Port Washington, NY: Kennikat Press.] 


\title{
POLICY RESEARCH DIVISION WORKING PAPERS
}

\author{
Recent Back Issues
}

1996

*83 Sajeda Amin, Ian Diamond, and Fiona Steele, "Contraception and religious practice in Bangladesh."

84 John B. Casterline, Aurora E. Perez, and Ann E. Biddlecom, "Factors underlying unmet need for family planning in the Philippines."

85 Geoffrey McNicoll, "Governance of fertility transition: Regularity and duress."

*86 John Bongaarts, "Population pressure and the food supply system in the developing world."

87 Sajeda Amin, "Family structure and change in rural Bangladesh."

*88 John Bongaarts and Susan Cotts Watkins, "Social interactions and contemporary fertility transitions."
*89 Cynthia B. Lloyd and Mark R. Montgomery, "The consequences of unintended fertility for investments in children: Conceptual and methodological issues."

* 90 Zeba Sathar and Sonalde Desai, "Work patterns in rural Pakistan: Intersections between gender, family, and class."

*91 Mark R. Montgomery, "Learning and lags in mortality perceptions."

92 Ann E. Biddlecom, John B. Casterline, and Aurora E. Perez, "Men's and women's views of contraception."
93 James F. Phillips, Fred N. Binka, Martin Adjuik, Alex Nazzar, and Kubaze Frank Adazu, "The determinants of contraceptive innovation: A case-control study of family planning acceptance in a traditional African society."
94 John Bongaarts and Sajeda Amin, "Prospects for fertility decline and implications for population growth in South Asia."

95 Barbara S. Mensch and Cynthia B. Lloyd, "Gender differences in the

* No longer available 
schooling experiences of adolescents in low-income countries: The case of Kenya."

96 Martin Brockerhoff and Ellen Brennan, "The poverty of cities in the developing world."

97 Carol E. Kaufman, "Reproductive control in South Africa."

98 John Bongaarts, "Trends in unwanted childbearing in the developing world."

99 Mary Arends-Kuenning, "How do family planning workers' visits affect women's contraceptive behavior in Bangladesh?"

100 Mark R. Montgomery and Cynthia B. Lloyd, "Excess fertility, unintended births, and children's schooling."
101 Mary Arends-Kuenning, “The equity and efficiency of doorstep delivery of contraceptives in Bangladesh."

102 Sajeda Amin, Ian Diamond, Ruchira T. Naved, and Margaret Newby, "Transition to adulthood of female factory workers: Some evidence from Bangladesh."

103 Margaret E. Greene and Ann E. Biddlecom, "Absent and problematic men: Demographic accounts of male reproductive roles."

104 Michael P. Todaro, "Urbanization, unemployment, and migration in Africa: Theory and policy."

105 Geoffrey McNicoll, "Population and poverty: A review and restatement."

\section{8}

106 Sajeda Amin and Gilda Sedgh, "Incentive schemes for school attendance in rural Bangladesh."

107 Martin Brockerhoff and Paul Hewett, "Ethnicity and child mortality in subSaharan Africa."
108 Ann E. Biddlecom and Bolaji M. Fapohunda, "Covert contraceptive use: Prevalence, motivations, and consequences."

109 John Bongaarts and Griffith Feeney, "On the quantum and tempo of fertility." 